\title{
Apoptosis induction of U937 human leukemia cells by diallyl trisulfide induces through generation of reactive oxygen species
}

Yung Hyun Choi ${ }^{1,2^{*}}$ and Hyun Soo Park

\begin{abstract}
Background: Diallyl trisulfide (DATS) is one of the major constituents in garlic oil and has demonstrated various pharmacological activities, including antimicrobial, antihyperlipidemic, antithrombotic, and anticancer effects. However, the mechanisms of antiproliferative activity in leukemia cells are not fully understood. In this study, the apoptotic effects of DATS were investigated in human leukemia cells.

Results: Results of this study indicated that treatment with DATS resulted in significantly inhibited leukemia cell growth in a concentration- and time-dependent manner by induction of apoptosis. In U937 cells, DATS-induced apoptosis was correlated with down-regulation of Bcl-2, XIAP, and CIAP-1 protein levels, cleavage of Bid proteins, activation of caspases, and collapse of mitochondrial membrane potential. The data further demonstrated that DATS increased intracellular reactive oxygen species (ROS) generation, which was attenuated by pretreatment with antioxidant N-acetyl-L-cysteine (NAC), a scavenger of ROS. In addition, administration of NAC resulted in significant inhibition of DATS-induced apoptosis by inhibiting activation of caspases.
\end{abstract}

Conclusions: The present study reveals that the cytotoxicity caused by DATS is mediated by generation of ROS and subsequent activation of the ROS-dependent caspase pathway in U937 leukemia cells.

Keywords: U937, DATS, Apoptosis, ROS, Caspase

\section{Background}

Reactive oxygen species (ROS), such as hydrogen peroxides $\left(\mathrm{H}_{2} \mathrm{O}_{2}\right)$, hydroxyl radicals $(\mathrm{OH} \cdot)$, and superoxide anions $\left(\cdot \mathrm{O}_{2}^{-}\right)$are commonly generated as a consequence of aerobic metabolism in mitochondria [1,2]. In normal physiological states, ROS are produced through electron leakage when molecular oxygen is used for ATP production in the mitochondrial electron transport chain [3-5]. As well as ROS production by mitochondria, these are also generated by various exogenous sources, such as chemicals and radiation [6-8]. Excessive accumulation of ROS results in severely demolished cellular macromolecules, such as DNA, and induces G2/M phase arrest by

\footnotetext{
* Correspondence: choiyh@deu.ac.kr
${ }^{1}$ Department of Biochemistry, Dongeui University College of Oriental

* Correspondence: choiyh@deu.ac.kr
${ }^{1}$ Department of Biochemistry, Dongeui University College of Oriental Medicine, San 45, Yangjung-dong Busanjin-gu, Busan 614-052, Republic of Korea
${ }^{2}$ Department of Biomaterial Control and Anti-Aging Research Center \& Korea
${ }^{2}$ Department of Biomaterial Control and Anti-Aging Research Center \& Blue-Bio Industry RIC, Dongeui University, 995 Eomgwangno Busanjin-gu, Busan 614-714, Republic of Korea
}

DNA damage [9-11]. Increased intracellular ROS also triggers apoptosis by activation of the intrinsic apoptotic pathway through induction of mitochondrial permeability transition and release of cytochrome $c$ from mitochondria to the cytosol [4,12-14].

Garlic (Allium sativum) is a common plant used mainly as food and has recently been reported to have medicinal properties [15-17]. Many researchers have recently demonstrated that sulfur-containing compounds, such as diallyl sulfide (DAS), diallyl disulfide (DADS), and diallyl trisulfide (DATS), which are major components of garlic, may be associated with reduced risk of certain cancers $[18,19]$. These compounds are known to inhibit cell proliferation and increase apoptosis in various cancer cell lines [20-22]. In particular, DATS containing three sulfur atoms against DAS and DADS have been known to have stronger biological activity, such as anti-cancer and anti-inflammatory effects [23-26]. Recently, Das et al. [27] have shown that DATS induces apoptosis through activation of ROS-dependent caspase 
activation in human glioblastoma cells. Others studies have also supported the notion that DATS induces dramatic ROS generation in cancer cells through a mitochondrial pathway $[26,28,29]$. However, the cellular and molecular mechanisms underlying the compound have yet not been completely elucidated.

In the present study, we hypothesized that DATS would also induce functional changes in mitochondria in association with ROS generation in the course of apoptosis induction in human leukemia cells. To test this hypothesis, we evaluated the effects of DATS on mitochondrial membrane potential (MMP) values, ROS generation, and apoptosis using the human leukemia U937 cell line. Our results indicated the requirement of ROS generation in apoptosis induced by DATS in U937 cells.

\section{Methods}

Reagents and antibodies

DATS was purchased from LKT Laboratories (St Paul, MN). 3-(4,5-dimetylthiazol-2-yl)-2,5-diphenyl-tetrazolium (MTT), propidium iodide (PI), 5,5', 6,6'-tetrachloro-1,1' 3,3 ' -tetraethyl-imidacarbocyanine iodide (JC1), 4,6-Diamidino-2-phenyllindile (DAPI), 5-(and 6)-carboxy-2'7'-dichlorodihydrofluorescein diacetate (DCFDA), and $N$-acetyl-L-cysteine (NAC) were purchased from Sigma-Aldrich (St. Louis, MO). Fetal bovine serum (FBS) and caspase activity assay kits were obtained from GIBCO-BRL (Gaithersburg, MD) and R\&D Systems (Minneapolis, MN), respectively. DNA staining kit (CycleTEST $^{\mathrm{TM}}$ PLUS Kit) and enhanced chemiluminescence (ECL) kit were purchased from Becton Dickinson (San Jose, CA) and Amersham (Arlington Heights, IL), respectively. All antibodies were purchased from Santa Cruz Biotechnology (Santa Cruz, CA).

\section{Cell culture and MTT assay}

The human leukemia cell lines used in our studies included human monocytic leukemia (U937 and THP-1 ), human acute myeloblastic leukemia (HL60) and human erythroid chronic myeloid leukemia (K562) were purchased from the American Type Culture Collection (Rockville, MD). They were maintained at $37^{\circ} \mathrm{C}$ in humidified $95 \%$ air and $5 \% \mathrm{CO}_{2}$ in RPMI1640 supplemented with $10 \%$ heat-inactivated FBS, 2 mM glutamine, $100 \mathrm{U} / \mathrm{ml}$ penicillin, and $100 \mu \mathrm{g} / \mathrm{ml}$ streptomycin. DATS was dissolved in dimethyl sulfoxide (DMSO) as a stock solution at a $100 \mathrm{mM}$ concentration, and the stock solution was then diluted with the medium to the desired concentration prior to use. For the cell viability study, cells were grown to $70 \%$ confluence and treated with DATS. Control cells were supplemented with complete media containing $0.1 \%$ DMSO (vehicle control). Following treatment, cell viability was determined by use of the
MTT assay, which is based on the conversion of MTT to MTT-formazan by mitochondrial enzymes [30]. The effect of DATS on inhibition of cell growth was assessed as the percentage of cell viability, where vehicle-treated cells were considered $100 \%$ viable.

\section{Nuclear staining with DAPI}

For DAPI staining, cells were washed with phosphatebuffered saline (PBS) and fixed with $3.7 \%$ paraformaldehyde (Sigma-Aldrich) in PBS for $10 \mathrm{~min}$ at room temperature. Fixed cells were washed with PBS and stained with $2.5 \mu \mathrm{g} / \mathrm{ml}$ DAPI solution for $10 \mathrm{~min}$ at room temperature. Cells were then washed twice with PBS and analyzed using a fluorescence microscope (Carl Zeiss, Germany).

\section{DNA fragmentation assay}

Following DATS treatment, cells were lysed in a buffer containing $10 \mathrm{mM}$ Tris- $\mathrm{HCl}, \mathrm{pH}$ 7.4, $150 \mathrm{mM} \mathrm{NaCl}, 5 \mathrm{mM}$ EDTA, and $0.5 \%$ Triton $\mathrm{X}-100$ for $1 \mathrm{~h}$ at room temperature. Lysates were vortexed and cleared by centrifugation at 19,000 g for $30 \mathrm{~min}$ at $4^{\circ} \mathrm{C}$. A 25:24:1 (v/v/v) equal volume of neutral phenol : chloroform : isoamyl alcohol (Sigma-Aldrich) was used for extraction of DNA in the supernatant, followed by electrophoretic analysis on $1.0 \%$ agarose gels containing $0.1 \mu \mathrm{g} / \mathrm{ml}$ ethidium bromide (EtBr, Sigma-Aldrich) [31].

\section{Measurement of cell cycle, mitochondrial membrane potential (MMP) values and ROS generation by a flow cytometer}

For analysis of the cell cycle, cells were collected, washed with cold PBS, and fixed in $75 \%$ ethanol at $4^{\circ} \mathrm{C}$ or 30 min. A DNA staining kit was used according to the manufacturer's instructions for measurement of the DNA content of the cells [32]. Flow cytometric analyses were carried out using a flow cytometer and the relative DNA content was determined using CellQuest software based on the presence of red fluorescence. MMP $(\Delta \Psi m)$ was determined using the dual-emission potentialsensitive probe, JC-1. Cells were collected and incubated with $10 \mu \mathrm{M} \mathrm{JC}-1$ for $20 \mathrm{~min}$ at $37^{\circ} \mathrm{C}$ in the dark. Cells were then washed once with PBS and analyzed using a flow cytometer [33]. For measurement of ROS generation, cells were treated with DATS for various periods and the medium was discarded; cells were then incubated with new culture medium containing $10 \mu \mathrm{M}$ of DCFDA at $37^{\circ} \mathrm{C}$ in the dark for $20 \mathrm{~min}$. Cell lysates were used for evaluation of ROS generation using a flow cytometer [34].

\section{Protein extraction and Western blotting}

Cells were harvested and washed twice in PBS at $4^{\circ} \mathrm{C}$. Total cells lysates were lysed in lysis buffer (40 mM Tris 
(pH 8.0), $120 \mathrm{mM}, \mathrm{NaCl}, 0.5$ \% NP-40, $0.1 \mathrm{mM}$ sodium orthovanadate, $2 \mu \mathrm{g} / \mathrm{ml}$ aprotinin, $2 \mu \mathrm{g} / \mathrm{ml}$ leupeptin, and $100 \mu \mathrm{g} / \mathrm{ml}$ phenymethylsulfonyl fluoride). Supernatants were collected and protein concentrations were then measured using protein assay reagents (Pierce, Rockford, IL). Equal amounts of protein extracts were denatured by boiling at $95^{\circ} \mathrm{C}$ for $5 \mathrm{~min}$ in sample buffer (0.5 M Tris- $\mathrm{HCl}, \mathrm{pH}$ 6.8, 4 \% SDS, 20 \% glycerol, $0.1 \%$ bromophenol blue, $10 \% \beta$-mercaptoethanol) at a ratio of 1:1, subjected to SDS-polyacrylamide gels, and transferred to polyvinylidene difluoride membranes (Schleicher \& Schuell, Keene, NH) by electroblotting. Membranes were blocked with $5 \%$ non-fat dry milk in PBS with Tween 20 buffer (PBS-T) (20 mM Tris, $100 \mathrm{mM} \mathrm{NaCl}, \mathrm{pH}$ 7.5, and $0.1 \%$ Tween 20) for $1 \mathrm{~h}$ at room temperature. Membranes were then incubated overnight at $4^{\circ} \mathrm{C}$ with the primary antibodies, probed with enzyme-linked secondary antibodies, and visualized using an ECL kit, according to the manufacturer's instructions.

\section{Caspase activity assay}

Activities of caspases were determined by use of colorimetric assay kits, which utilize synthetic tetrapeptides (Asp-Glu-Val-Asp (DEAD) for caspase-3; Ile-Glu-Thr -Asp (IETD) for caspase-8; Leu-Glu-His-Asp (LEHD) for caspase-9, respectively) labeled with p-nitroaniline (pNA). Briefly, DATS-treated and untreated cells were lysed in the supplied lysis buffer. Supernatants were collected and incubated with the supplied reaction buffer containing DTT and DEAD-pNA, IETD-pNA, or LEHD-pNA as substrates at $37^{\circ} \mathrm{C}$. The reactions were measured by changes in absorbance at $405 \mathrm{~nm}$ using the VERSAmax tunable microplate reader.

\section{Statistical analysis}

Unless otherwise indicated, each result is expressed as the mean $\pm S D$ of data obtained from triplicate experiments. Statistical analysis was performed using a paired Student t-test. Differences at $p<0.05$ were considered statistically significant.

\section{Results}

\section{Inhibition of cell viability by DATS in human leukemia cells}

To evaluate the effects of DATS on leukemia cell viability, four leukemia cell lines (U937, THP-1, HL60 and K562) were stimulated with various concentrations of DATS for $48 \mathrm{~h}$ or with $20 \mu \mathrm{M}$ DATS for the indicated times, and an MTT assay was performed. As shown in Figure 1, DATS induced a decrease in cell viability in a dose- and time-dependent manner in all four models of leukemia. For example, treatment with $20 \mu \mathrm{M}$ DATS for $24 \mathrm{~h}$ and $48 \mathrm{~h}$ in U937 cells resulted in $53 \%$ and $62 \%$ inhibition, respectively, which was associated with many morphological changes (Figure 2A).
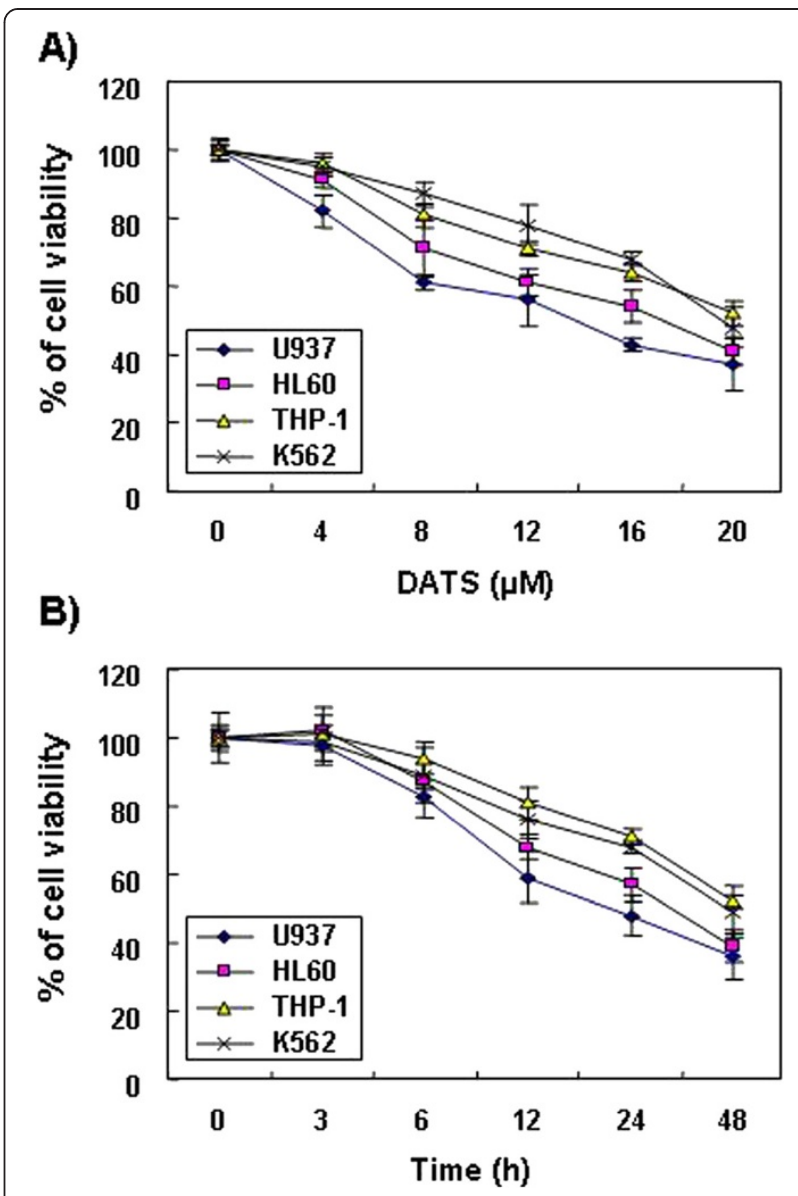

Figure 1 Inhibition of cell viability by DATS treatment in human leukemia cells. Cells (U937, THP-1, HL60 and K562) were plated at a concentration of $2.5 \times 10^{5}$ cells per $60-\mathrm{mm}$ plate. Following $24 \mathrm{~h}$ of stabilization, cells were treated with various concentrations of DATS for $48 \mathrm{~h}$ (A) or incubated with $20 \mu \mathrm{M}$ of DATS for the indicated times (B). Cell viability was determined by MTT assay. Results are expressed as percentage of the vehicle treated control $\pm S D$ of three separate experiments. A Student's t-test $\left({ }^{*}, p<0.05\right.$ vs. untreated control) was used for determination of significance.

Induction of apoptosis in human leukemia cells by DATS In order to determine whether the decrease in leukemia cell viability by DATS treatment was due to induction of apoptosis, three established criteria were subsequently used for assessment of apoptosis. First, morphological changes of cells were determined using DAPI staining; as shown in Figure $2 \mathrm{~B}$ and $\mathrm{C}$, treatment with DATS resulted in observation of a significant number of cells with chromatin condensation, loss of nuclear construction, and formation of apoptotic bodies, whereas these features were not observed in control cells. Second, we analyzed DNA fragmentation, which is another hallmark of apoptosis. Following agarose gel electrophoresis of DNAs from cells treated with DATS, a typical ladder pattern of internucleosomal fragmentation was observed. 


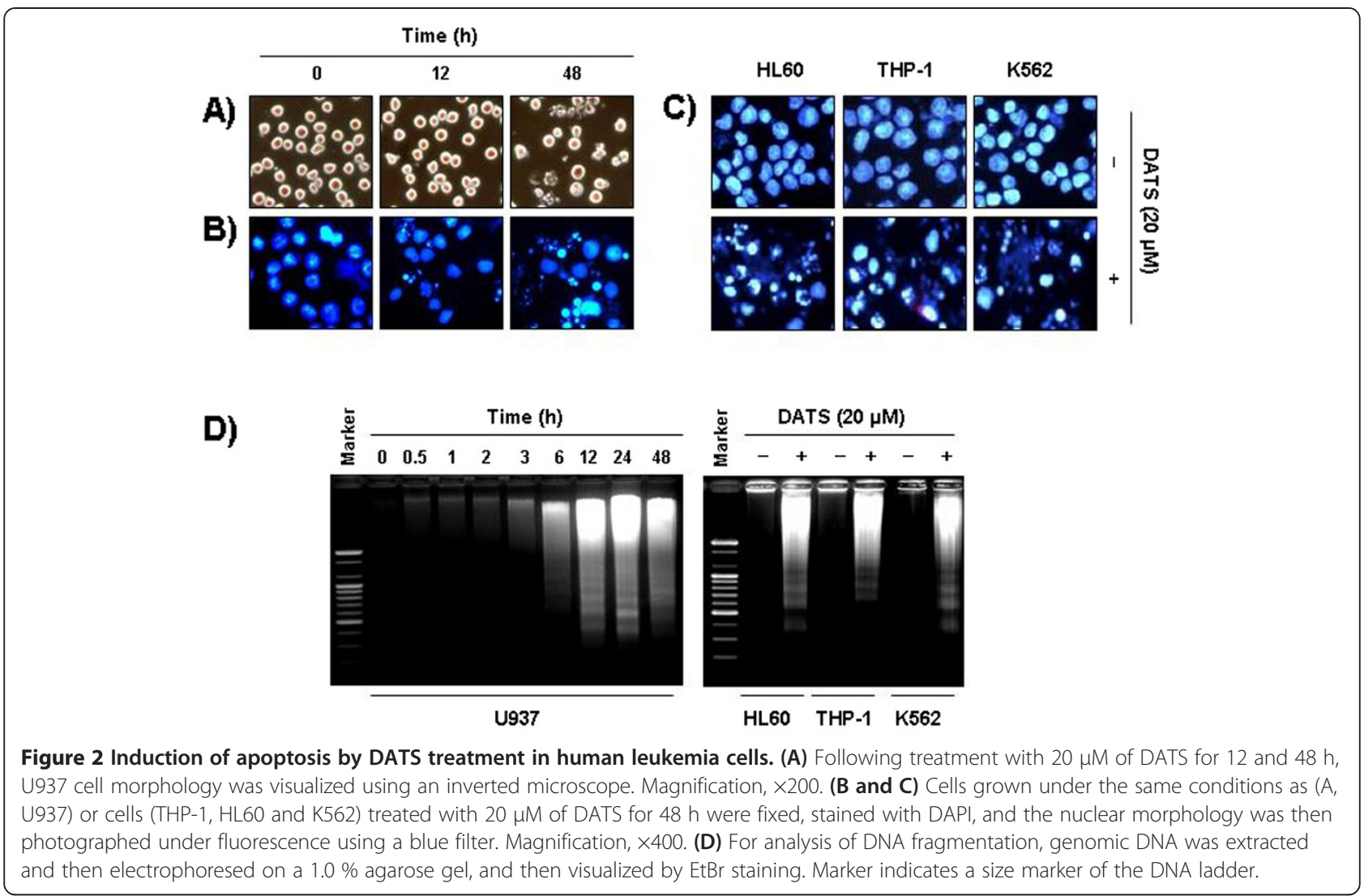

In contrast, DNA fragmentation in control cells was barely detected (Figure 2D). In addition, the degrees of apoptosis in cells treated with DATS were determined using flow-cytometric analysis for detection of hypodiploid cell populations. As shown in Figure 3, addition of DATS to leukemia cells resulted in increased accumulation of cells in the sub-G1 phase in a manner similar to that observed with DATS-induced viability inhibition, formation of apoptotic bodies, and accumulation of extranuclear fragmented DNA. This finding suggests that leukemia cells may undergo apoptosis after exposure to DATS, and there is a good correlation between the extent of apoptosis and inhibition of growth.

\section{Activation of caspases by DATS in U937 cells}

To reveal the mechanisms underlying the apoptotic effect of DATS on leukemia cells, we determined the expression levels and activities of caspase- $3,-8$, and -9 using U937 cells. As shown in Figure 4A, immunoblotting results showed that DATS treatment induced a concentrationdependent decrease in levels of procaspase- $3,-8$, and -9 proteins. For further quantification of the proteolytic activation of caspases, protein in the lysates of cells treated with DATS was normalized and then assayed for in vitro activities using fluorogenic substrates. As shown in Figure 4B, treatment with DATS resulted in a significant concentration-dependent increase of the activities of caspase-3, -8 , and -9 , compared with control cells. In addition, DATS treatment led to progressive proteolytic cleavage of poly(ADP-ribose) polymerase (PARP) and $\beta$ catenin, well-known substrate proteins of activated caspase3 , demonstrating an association of DATS-induced apoptosis with caspase activation.

\section{Effects of DATS on expression of Bcl-2 and IAP family proteins in U937 cells}

The role of Bcl-2 and IAP family proteins in DATSmediated apoptosis was determined by Western blotting for measurement of expression of Bcl-2 and IAP family members. As shown in Figure 5A, the levels of total Bid and $\mathrm{Bcl}-2$ proteins were decreased in response to DATS treatment; however the levels of pro-apoptotic Bax remained unchanged. In addition, the levels of antiapoptotic XIAP and cIAP-1 were also markedly inhibited by DATS treatment in a concentration-dependent manner.

\section{Loss of MMP values and increase of ROS generation by DATS in U937 cells}

Mitochondria, which play an essential role in apoptosis, are specialized organelles, which contain an outer membrane separated from an inner membrane by an intermembrane space that contains many proapoptotic 


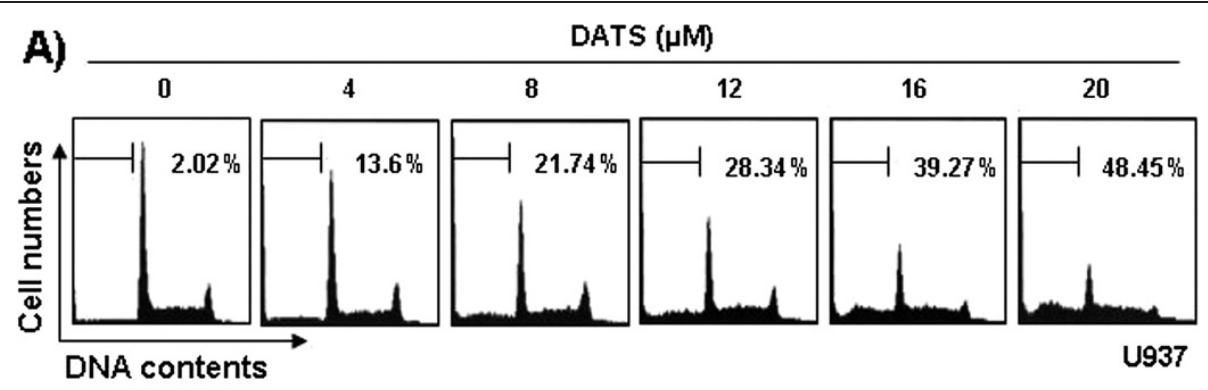

B)

DATS $(20 \mu \mathrm{M})$

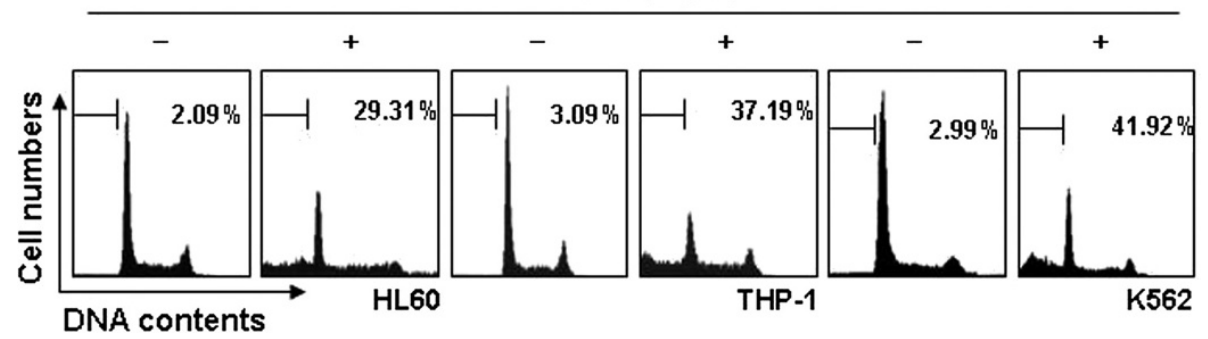

Figure 3 Increase of sub-G1 cell population by DATS treatment in human leukemia cells. Cells were treated with various concentrations of DATS for $48 \mathrm{~h}$ (A, U937) or incubated with 20 MM of DATS for $48 \mathrm{~h}$ (B, THP-1, HL60 and K562).To quantify the degree of apoptosis induced by DATS, cells were evaluated for sub-G1 DNA content, which represents the fractions undergoing apoptotic DNA degradation, using a flow cytometer. Data represent the mean of two independent experiments.

proteins, including cytochrome c. Decrease of MMP causes disruption of the outer mitochondrial membrane, which in turn contributes to release of cytochrome $c$. Because generation and acumination of ROS in cancer cells might be related to mitochondrial dysfunction and cell apoptosis, we attempted to characterize the relationship between ROS production and changes in the MMP. For this study, the effects of DATS on the levels of MMP were monitored via a flow cytometer using the mitochondrial-specific probe, JC-1. As shown in Figure 5B, MMP values showed a concentrationdependent decrease by DATS treatment, indicating that DATS induced mitochondrial membrane hyperpolarization by depolarization. Next, ROS production was measured using a cell-permeant, oxidation-sensitive dye, DCFDA. The results indicated that extending the time of DATS treatment to $0.5 \mathrm{~h}$ and $1 \mathrm{~h}$ resulted in increased ROS production to greater than 5.5 and 6.2 times that of the control, respectively (Figure 6A).

\section{DATS-induced apoptosis was associated with generation of ROS in U937 cells}

In order to show that generation of ROS is a key step in the DATS-induced apoptotic pathway, cells were pretreated with $10 \mathrm{mM}$ of NAC, a commonly used reactive oxygen intermediate scavenger, for $1 \mathrm{~h}$, followed by treatment with DATS for $48 \mathrm{~h}$. Blocking of ROS generation by pretreatment of cells with NAC effectively prevented DATS-induced down-regulation of $\mathrm{Bcl}-2$ and
XIAP expression, activation of caspases, and cleavage of PARP (Figure 6B). In addition, NAC had no effect on cell viability and apoptosis induction at a concentration of $10 \mathrm{mM}$; however, the presence of NAC almost completely suppressed DATS-induced apoptosis, as demonstrated by a near-complete reversal of the percentage of sub-G1 cells that were observed (Figure 7A), which was associated with recovered cell viability (Figure 7B). As expected, blocking of generation of ROS by pretreatment of cells with NAC also prevented DATS-induced chromatin condensation (Figure 7C). Collectively, these findings suggest that an increase in ROS generation is required for occurrence of DATS-induced apoptosis in U937.

\section{Discussion}

Although an increasing amount of data indicate that DATS can suppress the growth of cultured cancer cells by causing cell cycle arrest at G2/M phase and generation of apoptosis [26-29,35-37], little is known about the effects of this compound on the growth of human leukemia cells. In the present study, we demonstrated that DATS-induced anti-proliferative effects in four leukemia cell lines (U937, THP-1, HL60 and K562) were related to induction of apoptosis, as confirmed by measurement of chromatin condensation of nuclei, DNA fragmentation, and induction of sub-G1 phase. Our data also indicated that DATS induced apoptosis of U937 cells through generation of ROS and mitochondrial 
A)

\begin{tabular}{cccccc}
\multicolumn{9}{c}{ DATS $(\mu \mathrm{M})$} \\
\hline 0 & 4 & 8 & 12 & 16 & 20
\end{tabular}

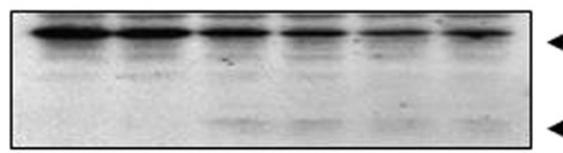

Pro-caspase 3

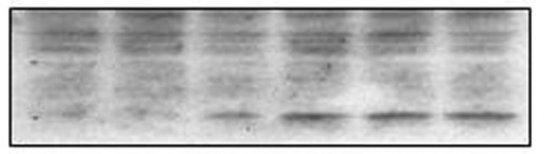

$\leftarrow$ Active-caspase-3

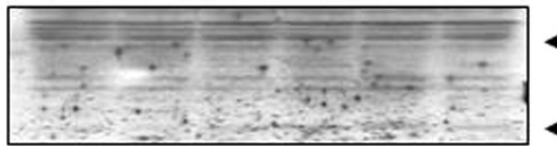

$\leftarrow$ Pro-caspase-8

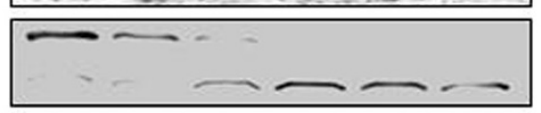

$\leftarrow$ Active-caspase-8
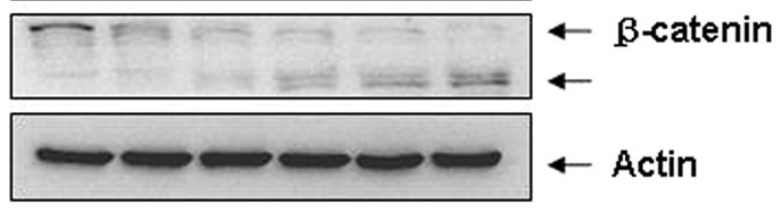

B)

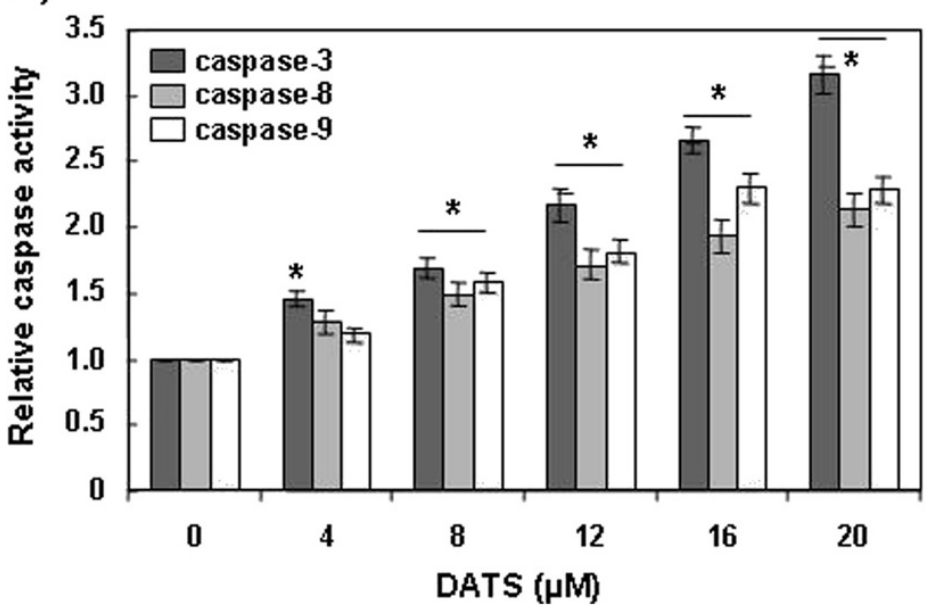

Figure 4 Activation of caspases and degradation of PARP and $\beta$-catenin protein by DATS treatment in U937 cells. Cells were treated with the indicated concentration of DATS for $48 \mathrm{~h}$. (A) Cells were lysed and then equal amounts of cell lysates (30 $\mathrm{\mu g}$ ) were separated on SDSpolyacrylamide gels and transferred to nitrocellulose membranes. Membranes were probed with the indicated antibodies. An ECL detection system was used for visualization of proteins. Actin was used as an internal control. (B) Cells grown under the same conditions as (A) were collected and lysed. Aliquots were incubated with DEVD-pNA, IETD-pNA, and LEHD-pNA for caspase-3, -8, and -9, individually, at 37 for 1 h. Released fluorescence products were measured. Each point represents the mean \pm the SD of representative experiments performed at least three times. A Student's t-test ( ${ }^{*}, p<0.05$ vs. untreated control) was used for analysis of statistical significance of the results.

dysfunction, suggesting that ROS act as upstream signaling molecules for initiation of cell death.

Mounting evidence suggests that damaged mitochondria stimulate increased ROS production, subsequently resulting in activation of the signaling pathways that control cancer cell growth. However, loss of MMP as a result of mitochondrial depolarization in association with apoptosis appears to be more common. The mechanisms by which ROS cause or regulate apoptosis typically include caspase activation and modulation of $\mathrm{Bcl}-2$ family protein expression [38,39]. Caspases, a family of cystein-containing aspartate-specific proteases, are known to play key roles during apoptosis and to lead to initiation and execution of apoptosis. Activation of initiator caspases, such as caspase- 8 and -9 , resulted in downstream activation of effector caspases, such as caspase-3 and -7 [40,41]. The decrease in MMP causes disruption of the outer mitochondrial membrane and contributes to release of cytochrome $c$. Release of cytochrome $c$ 


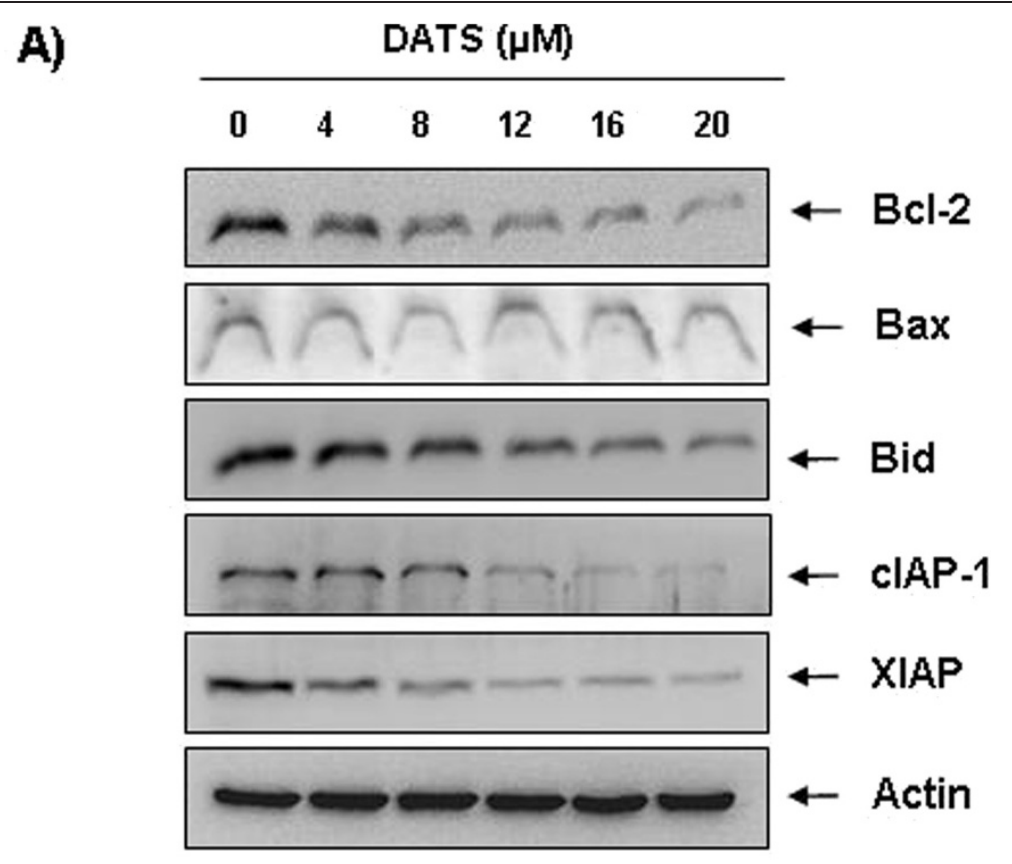

B)

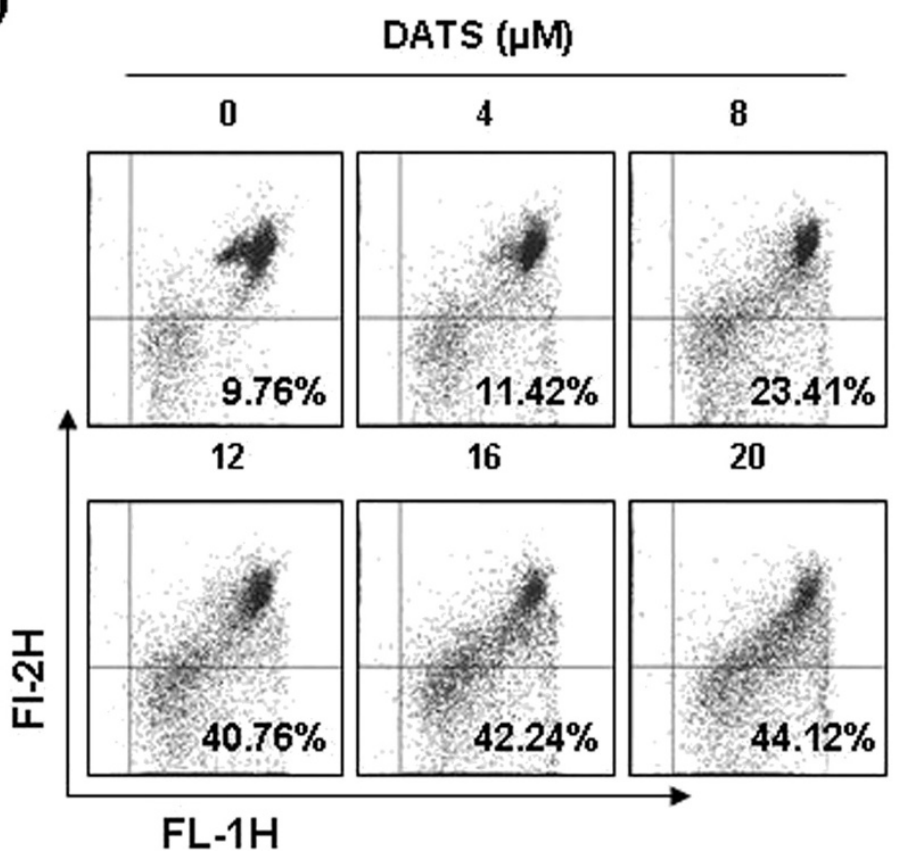

Figure 5 Effects of DATS on levels of Bcl-2 and IAP family proteins, and MMP values in U937 cells. (A) Cells were treated with the indicated concentration of DATS for $48 \mathrm{~h}$. Cells were lysed and then equal amounts of cell lysates $(30 \mu \mathrm{g})$ were separated on SDS-polyacrylamide gels and transferred to nitrocellulose membranes. Membranes were probed with the indicated antibodies and the proteins were visualized using an ECL detection system. Actin was used as an internal control. (B) Cells grown under the same conditions as (A) were stained with JC-1 and incubated at $37^{\circ} \mathrm{C}$ for 20 min. Mean JC-1 fluorescence intensity was detected using a flow cytometer. Data represent the means of two independent experiments.

has been reported to contribute to activation of caspase-9, which in turn causes activation of caspase-3. In particular, activation of capase-3 is responsible for proteolytic degradation of many key proteins, including PARP and $\beta$-catenin, finally leading to apoptosis $[42,43]$. Modulation of anti- and pro-apoptotic proteins of the $\mathrm{Bcl}-2$ family also controls mitochondrial function. In mammals, members of the Bcl2 family can be divided into two subfamilies; the antiapoptotic protein family, including $\mathrm{Bcl}-2$, and the proapoptotic protein family, including Bax. Balance between 

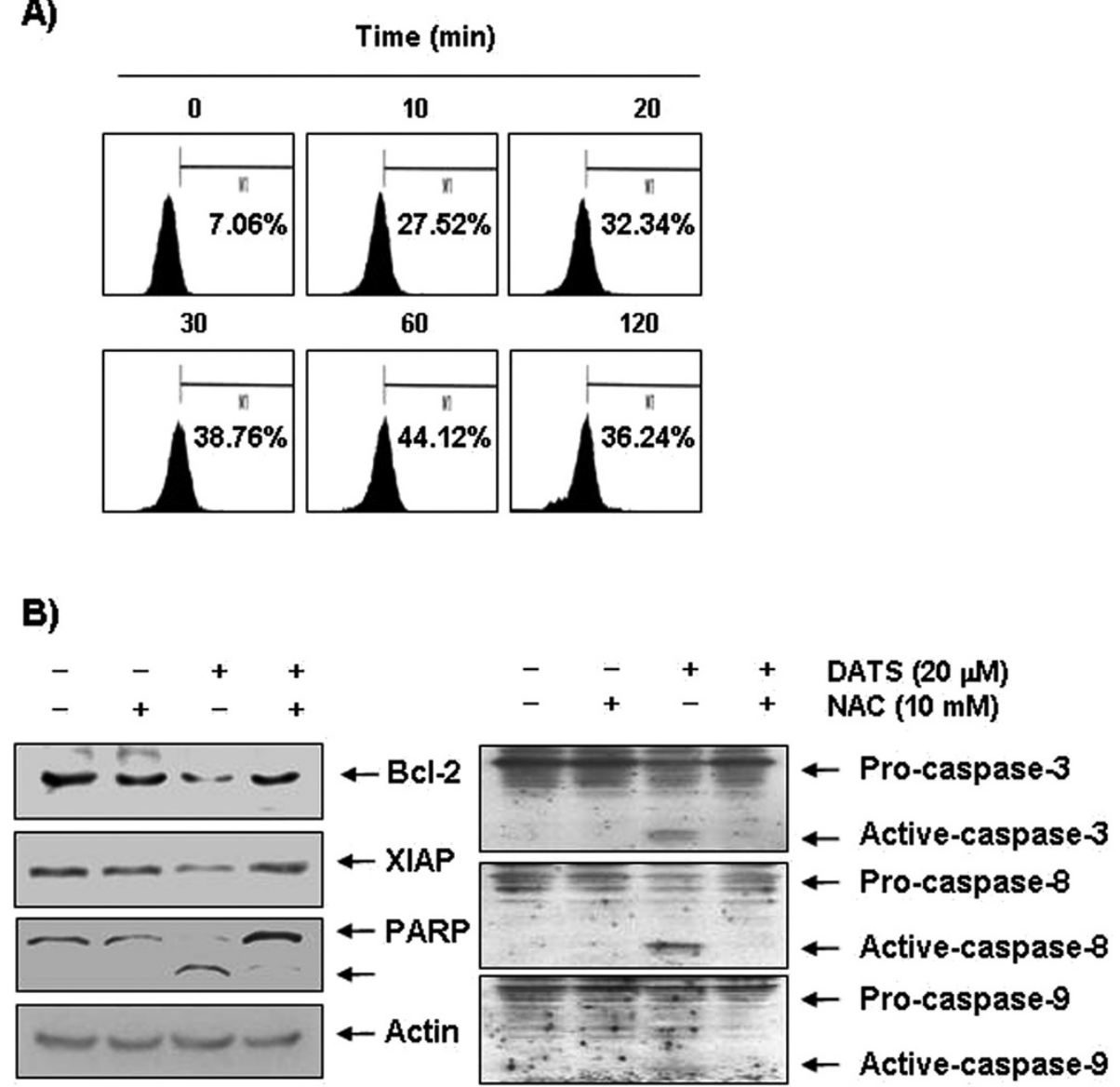

Figure 6 ROS generation and effects of NAC treatment on modulation of Bcl-2, XIAP, caspases and PARP proteins by DATS in U937 cells. (A) Cells treated with $20 \mu \mathrm{M}$ of DATS for the indicated times were incubated with $10 \mu \mathrm{M}$ of DCFDA at $37^{\circ} \mathrm{C}$ for 20 min, and ROS generation was measured using a flow cytometer. Results are expressed as the mean of two independent experiments. (B) Cells were treated with or without NAC (10 mM) for $1 \mathrm{~h}$ before challenge with $20 \mu \mathrm{M}$ of DATS for $48 \mathrm{~h}$. Cellular proteins were then lysed and separated by SDSpolyacrylamide gels and transferred onto nitrocellulose membranes. Membranes were probed with the indicated antibodies. Proteins were visualized using an ECL detection system. Actin was used as an internal control.

anti-apoptotic and pro-apoptotic members also determines the fate of the cell through mitochondrial dysfunction $[44,45]$. In addition, activation of caspase- 8 by apoptotic stimuli converts Bid to truncated Bid (tBid), leading to conformational changes in Bax, mitochondrial depolarization, and release of cytochrome $c$ from mitochondria. This leads finally to activation of caspase- 3 and induction of apoptosis via a complex of apoptotic protease activating factor-1 (Apaf-1), procaspase-9, and cytochrome $c$ after translocation of tBid to the mitochondria [41,44-46]. Furthermore, members of the IAP family, which includes XIAP, cIAP-1, and cIAP-2, have been reported to exert their antiapoptotic effects due to their function as direct inhibitors of activated caspases. Therefore, down-regulation of IAPs relieves the triggering block of proapoptotic signaling and execution of caspases, thus activating cell death $[47,48]$.

In this study, our data indicated an association of DATSinduced apoptosis of U937 cells with increased generation of ROS and enzymatic activity of both the extrinsic and intrinsic caspase cascades, including caspase- 8 and -9 . Although the truncated form of Bid fwas not detected, the levels of intact Bid proteins were gradually down-regulated by DATS in a concentration-dependent manner. DATS also caused a significant reduction in MMP values, which was connected with activation of caspase- 3 and concomitant degradation of PARP and $\beta$-catenin. In addition, downregulation of anti-apoptotic Bcl-2 and IAP family proteins, including Bcl-2, XIAP, and cIAP-1, was observed in U937 cells exposed to DATS, as compared with control cells. Thus, the results indicated that caspase- 8 activation by DATS appeared to trigger mitochondrial apoptotic events by inducing conformational changes in apoptotic proteins.

ROS-mediated caspase activation and mitochondrial dysfunction have been suggested as critical for DATSinduced apoptosis in several cancer cell lines [26-29]; however, the current role of mitochondrial functional 


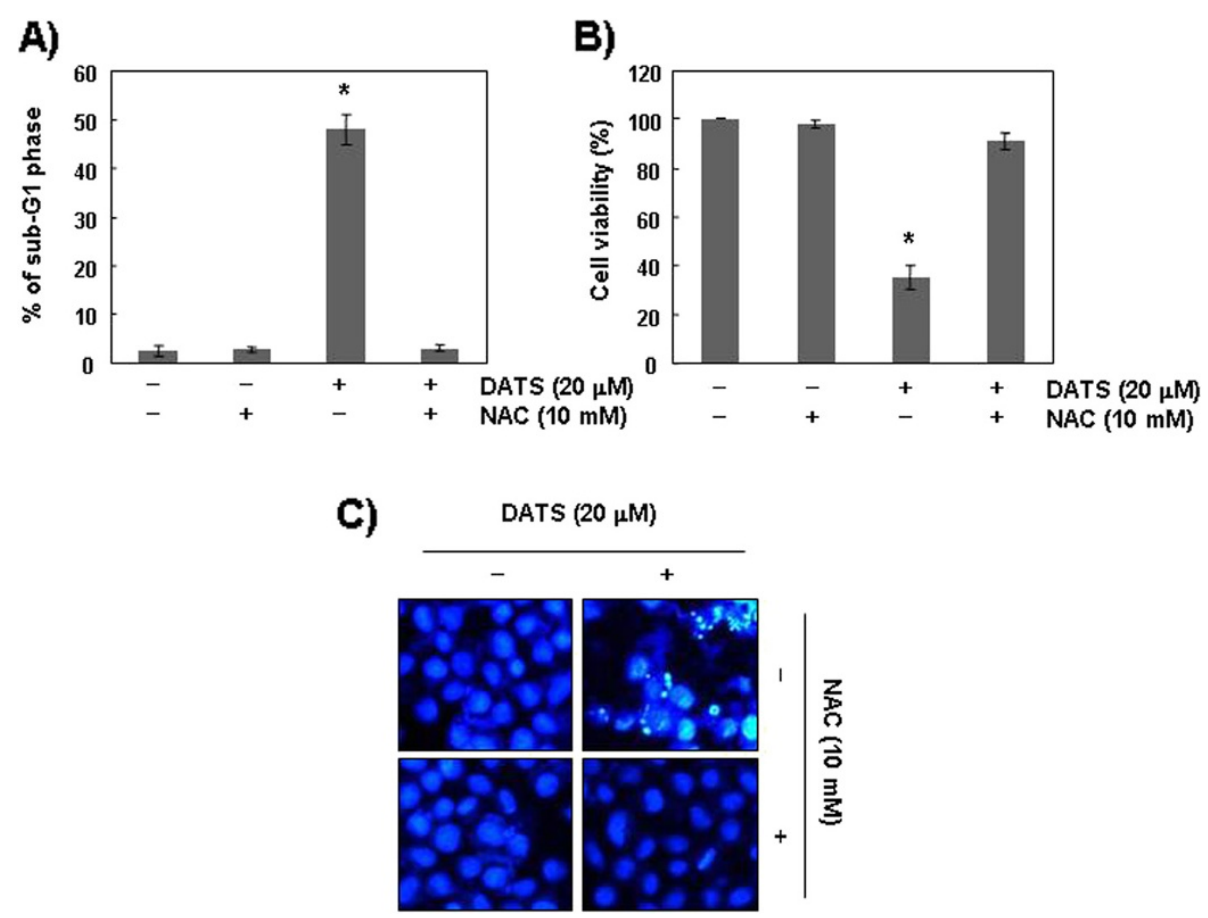

Figure 7 DATS-induced apoptosis is associated with ROS generation in U937 cells. Cells were incubated with $20 \mu \mathrm{M}$ of DATS for $48 \mathrm{~h}$ after pretreatment with or without $10 \mathrm{mM}$ of NAC. Cells were evaluated for sub-G1 DNA content using a flow cytometer (A) and cell viability was determined using the MTT assay (B). Data are expressed as overall means \pm SD from three independent experiments. Statistical significance was determined using the Student's t-test ( ${ }^{*} P<0.05$ vs. vehicle control). (C) Following incubation of cells under the same conditions, cells were fixed, stained with DAPI, and the nuclear morphology was then photographed under fluorescence using a blue filter. Magnification, $\times 400$.

changes associated with ROS generation in the response of human leukemia cells to DATS has not yet been explored. Therefore, we next investigated the question of whether these observations and apoptosis by DATS in U937 cells were associated with generation of ROS. The results revealed that activation of caspase- 9 and -3 , degradation of PARP, and inhibition of Bcl-2 in DATS-treated cells were ROS-dependent and that co-culture with NAC, a commonly used ROS scavenger, effectively blocked DATS-induced apoptosis in U937 cells. Findings from the present study also indicated that activation of caspase- 8 in DATS-treated cells is ROS-dependent, which suggests that ROS may act upstream of caspase- 8 activation in U937 cells. Therefore, it is reasonable to assume that the initial signal for activation of caspase- 8 after treatment with DATS is also derived from ROS. In addition, blocking of ROS generation prevented DATS-induced down-regulation of XIAP and cIAP-1. Because IAP family proteins are also substrates of caspase-3 [49,50], the observed decrease in XIAP and cIAP-1 expression may be due to caspase-3-mediated processing following DATS treatment. Thus, our data indicate that ROS production and mitochondrial dysfunction are possible contributing factors to DATS toxicity.

\section{Conclusions}

In summary, the present study demonstrated that human leukemia cells undergo apoptosis in response to treatment with DATS, and that this occurs through a mitochondria-mediated pathway that requires ROS generation upstream for disruption of the MMP, which leads to subsequent activation of caspases. Although in this paper we only performed a rough assessment for determination of whether ROS was involved in the apoptosis induced by DATS, our data emphasize the key role of ROS in apoptosis induced by DATS in U937 cells, and indicate that a positive correlation exists between ROS and mitochondrial events leading to apoptosis, and may aid in understanding of the mechanisms for the anticancer activity of DATS.

\section{Competing interests}

The authors declare no potential conflict of interests.

\section{Acknowledgements}

This work was supported by a grant (Code \#7-19-42) from Rural Development Administration, Republic of Korea

Authors' contributions

HSP carried out major experiments in the study and helped to draft the manuscript with YHC. YHC contributed to the experimental design, data interpretation, editing, and submission of this manuscript. All authors read and approved the final manuscript. 
Received: 21 January 2012 Accepted: 11 May 2012

Published: 11 May 2012

\section{References}

1. Inoue M, Sato EF, Nishikawa M, Park AM, Kira Y, Imada I, Utsumi K Mitochondrial generation of reactive oxygen species and its role in aerobic life. Curr Med Chem 2010, 10:2495-2505.

2. Liu Y, Fiskum G, Schubert D: Generation of reactive oxygen species by the mitochondrial electron transport chain. J Neurochem 2002, 80:780-787.

3. Le Bras M, Clément MV, Pervaiz S, Brenner C: Reactive oxygen species and the mitochondrial signaling pathway of cell death. Histol Histopathol 2005, 20:205-219.

4. Orrenius $\mathrm{S}$ : Reactive oxygen species in mitochondria-mediated cell death. Drug Metab Rev 2007, 39:443-455

5. Fang J, Seki T, Maeda H: Therapeutic strategies by modulating oxygen stress in cancer and inflammation. Adv Drug Deliv Rev 2009, 61:290-302.

6. Pillai $\mathrm{S}$, Oresajo $\mathrm{C}$, Hayward J: Ultraviolet radiation and skin aging: roles of reactive oxygen species, inflammation and protease activation, and strategies for prevention of inflammation-induced matrix degradation - a review. Int J Cosmet Sci 2005, 27:17-34.

7. Christofidou-Solomidou M, Muzykantov VR: Antioxidant strategies in respiratory medicine. Treat Respir Med 2006, 5:47-78,

8. Kovacic P, Somanathan R: Dermal toxicity and environmental contamination: electron transfer, reactive oxygen species, oxidative stress, cell signaling, and protection by antioxidants. Rev Environ Contam Toxicol 2010, 203:119-138.

9. Burhans WC, Heintz NH: The cell cycle is a redox cycle: linking phase-specific targets to cell fate. Free Radic Biol Med 2009, 47:1282-1293.

10. Tuteja N, Ahmad P, Panda BB, Tuteja R: Genotoxic stress in plants: shedding light on DNA damage, repair and DNA repair helicases. Mutat Res 2009, 681:134-149.

11. Pandey AN, Tripathi A, Premkumar KV, Shrivastav TG, Chaube SK: Reactive oxygen and nitrogen species during meiotic resumption from diplotene arrest in mammalian oocytes. J Cell Biochem 2010, 111:521-528.

12. Ling $Y H$, Liebes $L$, Zou Y, Perez-Soler R: Reactive oxygen species generation and mitochondrial dysfunction in the apoptotic response to Bortezomib, a novel proteasome inhibitor, in human $\mathrm{H} 460$ non-small cell lung cancer cells. J Biol Chem 2003, 278:33714-33123.

13. Moungjaroen J, Nimmannit U, Callery PS, Wang L, Azad N, Lipipun V, Chanvorachote $P$, Rojanasakul Y: Reactive oxygen species mediate caspase activation and apoptosis induced by lipoic acid in human lung epithelial cancer cells through Bcl-2 down-regulation. J Pharmacol Exp Ther 2006, 319:1062-1069.

14. Niizuma K, Yoshioka H, Chen H, Kim GS, Jung JE, Katsu M, Okami N, Chan $\mathrm{PH}:$ Mitochondrial and apoptotic neuronal death signaling pathways in cerebral ischemia. Biochim Biophys Acta 2010, 1802:92-99.

15. Iciek M, Kwiecień I, Włodek L: Biological properties of garlic and garlic-derived organosulfur compounds. Environ Mol Mutagen 2009, 50:247-265

16. Swiderski F, Dabrowska M, Rusaczonek A, Waszkiewicz-Robak B: Bioactive substances of garlic and their role in dietoprophylaxis and dietotherapy. Rocz Panstw Zakl Hig 2007, 58:41-46.

17. Gayathri R, Gunadharini DN, Arunkumar A, Senthilkumar K, Krishnamoorthy G, Banudevi S, Vignesh RC, Arunakaran J: Effects of diallyl disulfide (DADS) on expression of apoptosis associated proteins in androgen independent human prostate cancer cells (PC-3). Mol Cell Biochem 2009, 320:197-203.

18. Aggarwal BB, Shishodia S: Molecular targets of dietary agents for prevention and therapy of cancer. Biochem Pharmacol 2006 71:1397-1421

19. Kaschula $\mathrm{CH}$, Hunter R, Parker Ml: Garlic-derived anticancer agents: structure and biological activity of ajoene. Biofactors 2010, 36:78-85.

20. Yang JS, Chen GW, Hsia TC, Ho HC, Ho CC, Lin MW, Lin SS, Yeh RD, Ip SW, Lu HF, Chung JG: Diallyl disulfide induces apoptosis in human colon cancer cell line (COLO 205) through the induction of reactive oxygen species, endoplasmic reticulum stress, caspases casade and mitochondrial-dependent pathways. Food Chem Toxicol 2009, 47:171-179

21. Powolny AA, Singh SV: Multitargeted prevention and therapy of cancer by diallyl trisulfide and related Allium vegetable-derived organosulfur compounds. Cancer Lett 2008, 269:305-314.
22. Druesne-Pecollo N, Pagniez A, Thomas M, Cherbuy C, Duée PH, Martel P, Chaumontet C: Diallyl disulfide increases CDKN1A promoter-associated histone acetylation in human colon tumor cell lines. J Agric Food Chem 2006, 54:7503-7507.

23. Wu CC, Chung JG, Tsai SJ, Yang JH, Sheen LY: Differential effects of allyl sulfides from garlic essential oil on cell cycle regulation in human liver tumor cells. Food Chem Toxicol 2004, 42:1937-1947.

24. Münchberg U, Anwar A, Mecklenburg S, Jacob C: Polysulfides as biologically active ingredients of garlic. Org Biomol Chem 2007, 5:1505-1518.

25. Liu KL, Chen HW, Wang RY, Lei YP, Sheen LY, Lii CK: DATS reduces LPS-induced iNOS expression, NO production, oxidative stress, and NF-KB activation in RAW 264.7 macrophages. J Agric Food Chem 2006, 54:3472-3478

26. Wang HC, Yang JH, Hsieh SC, Sheen LY: Allyl sulfides inhibit cell growth of skin cancer cells through induction of DNA damage mediated G2/M arrest and apoptosis. J Agric Food Chem 2010, 58:7096-7103.

27. Das A, Banik NL, Ray SK: Garlic compounds generate reactive oxygen species leading to activation of stress kinases and cysteine proteases for apoptosis in human glioblastoma T98G and U87MG cells. Cancer 2007, 110:1083-1095.

28. Kim YA, Xiao D, Xiao H, Powolny AA, Lew KL, Reilly ML, Zeng Y, Wang Z, Singh SV: Mitochondria-mediated apoptosis by diallyl trisulfide in human prostate cancer cells is associated with generation of reactive oxygen species and regulated by Bax/Bak. Mol Cancer Ther 2007, 6:1599-1609.

29. Lee BC, Park BH, Kim SY, Lee YJ: Role of Bim in diallyl trisulfide-induced cytotoxicity in human cancer cells. J Cell Biochem 2011, 112:118-127.

30. Zhang C, Li Y, Shi X, Kim SK: Inhibition of the expression on MMP-2, 9 and morphological changes via human fibrosarcoma cell line by 6,6'-bieckol from marine alga Ecklonia cava. BMB Rep 2010, 43:62-68.

31. Paul S, Mandal SK, Bhattacharyya SS, Boujedaini N, Khuda-Bukhsh AR: In vitro and in vivo studies demonstrate anticancer property of root extract of Polygala senega. J Acupunct Meridian Stud 2010, 3:188-196.

32. Ryu DS, Baek GO, Kim EY, Kim KH, Lee DS: Effects of polysaccharides derived from Orostachys japonicus on induction of cell cycle arrest and apoptotic cell death in human colon cancer cells. BMB Rep 2010, 43:750-755.

33. Choi JH, Choi AY, Yoon H, Choe W, Yoon KS, Ha J, Yeo EJ, Kang I: Baicalein protects HT22 murine hippocampal neuronal cells against endoplasmic reticulum stress-induced apoptosis through inhibition of reactive oxygen species production and CHOP induction. Exp Mol Med 2010, 42:811-822.

34. Kim SY, Kang HT, Choi HR, Park SC: Biliverdin reductase A in the prevention of cellular senescence against oxidative stress. Exp Mol Med 2011, 43:15-23.

35. Xiao D, Zeng $Y$, Singh SV: Diallyl trisulfide-induced apoptosis in human cancer cells is linked to checkpoint kinase 1-mediated mitotic arrest. Mol Carcinog 2009, 48:1018-1029.

36. Antosiewicz J, Herman-Antosiewicz A, Marynowski SW, Singh SV: c-Jun NH (2)-terminal kinase signaling axis regulates diallyl trisulfide-induced generation of reactive oxygen species and cell cycle arrest in human prostate cancer cells. Cancer Res 2006, 66:5379-5386.

37. Herman-Antosiewicz A, Powolny AA, Singh SV: Molecular targets of cancer chemoprevention by garlic-derived organosulfides. Acta Pharmacol Sin 2009, 28:1355-1364.

38. Takahashi A, Masuda A, Sun M, Centonze VE, Herman B: Oxidative stress-induced apoptosis is associated with alterations in mitochondrial caspase activity and $\mathrm{Bcl}$-2-dependent alterations in mitochondrial $\mathrm{pH}$ (pHm). Brain Res Bull 2004, 62:497-504.

39. Ryter SW, Kim HP, Hoetzel A, Park JW, Nakahira K, Wang X, Choi AM: Mechanisms of cell death in oxidative stress. Antioxid Redox Signal 2007, 9:49-89.

40. Scaffidi C, Fulda S, Srinivasan A, Friesen C, Li F, Tomaselli K, Debatin KM, Krammer PH, Peter ME: Two CD95 (APO-1/Fas) signaling pathways. EMBO J 1998, 17:1675-1687.

41. Ly JD, Grubb DR, Lawen A: The mitochondrial membrane potential (deltapsi(m)) in apoptosis; an update. Apoptosis 2003, 8:115-128.

42. Lazebnik YA, Kaufmann SH, Desnoyers S, Poirier GG, Earnshaw WC Cleavage of poly(ADP-ribose) polymerase by a proteinase with properties like ICE. Nature 1994, 371:346-347.

43. Fukuda K: Apoptosis-associated cleavage of $\beta$-catenin in human colon cancer and rat hepatoma cells. Int J Biochem Cell Biol 1999, 31:519-529. 
44. Jin Z, El-Deiry WS: Overview of cell death signaling pathways. Cancer Biol Ther 2005, 4:139-163.

45. Kroemer G, Reed JC: Mitochondrial control of cell death. Nat Med 2000 6:513-519

46. Shelton SN, Shawgo ME, Robertson JD: Cleavage of Bid by executioner caspases mediates feed forward amplification of mitochondrial outer membrane permeabilization during genotoxic stress-induced apoptosis in Jurkat cells. Biol Chem 2009, 284:11247-11255.

47. Deveraux QL, Reed JC: IAP family proteins-suppressors of apoptosis. Genes Dev 1999, 13:239-252

48. Roy N, Deveraux QL, Takahashi R, Salvesen GS, Reed JC: The C-IAP-1 and C-IAP-2 proteins are direct inhibitors of specific caspases. EMBO J 1997, 16:6914-6925.

49. Hell K, Saleh M, Crescenzo GD, O'Connor-McCourt MD, Nicholson DW: Substrate cleavage by caspases generates protein fragments with Smac/ Diablo-like activities. Cell Death Differ 2003, 10:1234-1239.

50. Choi YE, Butterworth M, Malladi S, Duckett CS, Cohen GM, Bratton SB: The E3 ubiquitin ligase CIAP1 binds and ubiquitinates caspase-3 and -7 via unique mechanisms at distinct steps in their processing. J Biol Chem 2009, 284:12772-12782.

doi:10.1186/1423-0127-19-50

Cite this article as: Choi and Park: Apoptosis induction of U937 human leukemia cells by diallyl trisulfide induces through generation of reactive oxygen species. Journal of Biomedical Science 2012 19:50.

\section{Submit your next manuscript to BioMed Central and take full advantage of:}

- Convenient online submission

- Thorough peer review

- No space constraints or color figure charges

- Immediate publication on acceptance

- Inclusion in PubMed, CAS, Scopus and Google Scholar

- Research which is freely available for redistribution 